\title{
МЕТОДИКА РАСЧЕТА ВЕЛИЧИНЫ КРУТЯЩЕГО МОМЕНТА НАСТРОЙКИ ЭЛЕКТРОПРИВОДА В СИСТЕМЕ ЭЛЕКТРОПРИВОДНОЙ ЗАПОРНОЙ АРМАТУРЫ С ПРЯМОЛИНЕЙНЫМ ПЕРЕМЕЩЕНИЕМ ЗАПОРНОГО ОРГАНА
}

\author{
С.А.ВАСИН, Е.В.ПЛАХОТНИКОВА
}

Тульский государственный университет, Тула, Россия

\begin{abstract}
Представлена новая методика расчета величины крутящего момента настройки электропривода в системах электроприводной запорной арматуры как основных элементов, обеспечивающих безопасность нефтяных трубопроводов и магистральных газопроводов. Методика позволяет при минимальном объеме входной информации о характеристиках элементов системы (электропривода, запорной арматуры, системы управления) произвести расчет достаточного значения крутящего момента настройки электропривода и гарантировать соответствие фактического крутящего момента при полной остановке системы расчетному крутящему моменту, установленному статическими методами. Уточнение параметров настройки проводится путем экспериментального определения протечек среды при пошаговом снижении крутящего момента в пределах регулирования электропривода. Использование методики на стадии проектирования позволяет при эксплуатации систем снизить нежелательные нагрузки, возникающие в запорной арматуре со стороны электропривода, обеспечивая надежную работу трубопроводных систем, транспортирующих минеральное сырье.

Ключевые слова: электроприводная запорная арматура; методика силового расчета; надежность; качество
\end{abstract}

Как цитировать эту статью: Васин С.А. Методика расчета величины крутящего момента настройки электропривода в системе электроприводной запорной арматуры с прямолинейным перемещением запорного органа / С.А.Васин, Е.В.Плахотникова // Записки Горного института. 2018. Т. 232. С. 407-412. DOI: 10.31897/PMI.2018.4.407

Введение. На сегодняшний день для доставки более 30 \% минерального сырья (основная масса нефти и газ) в России используется трубопроводный транспорт. Российская газотранспортная система является крупнейшей в мире и составляет более 165 тыс. км. Протяженность магистральных нефтепроводов, предназначенных для транспортировки нефти из районов их добычи или хранения до мест потребления, превышает 70 тыс. км. Неотъемлемой частью трубопроводной системы является запорная арматура. Она предназначена для отсекания участка трубопровода при аварии или ремонтных работах. На линейной части трубопроводов запорная арматура установлена через каждые 10-30 км.

Преобладающее большинство трубопроводной арматуры управляется дистанционно, электроприводом. Это позволяет использовать системы электроприводной запорной арматуры в самых протяженных и сложных по конфигурации трубопроводах. Характеристиками, определяющими возможность технического совмещения электропривода и запорной арматуры в рамках системы, являются силовые параметры: крутящий момент и усилия.

Методики силовых расчетов ручной запорной арматуры различных отечественных производителей основаны на единых принципах, сформулированных классиком арматуростроения Д.Ф.Гуревичем в начале 60-х годов прошлого века [3]. Они проверены временем и объединены стандартами ЦКБА (Центральное конструкторское бюро арматуростроения, Санкт-Петербург). К сожалению, в указанных документах отсутствуют методики для расчета электроприводной арматуры.

В соответствии со стандартами для электроприводной арматуры крутящий момент закрытия

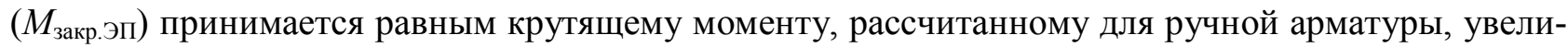
ченному на коэффициент запаса [7]:

$$
M_{\text {закр.ЭП }}=K_{3} M_{\text {закр.руч }}
$$

где $K_{3}$ - коэффициент запаса по необходимому крутящему моменту на приводе, для электропривода $K_{3}=1,1 \div 1,25$.

Указанный подход, по нашему мнению, является неверным. Он приводит к снижению надежности электроприводной арматуры и безопасности эксплуатирующих данный вид оборудования предприятий $[1,9,15]$. 
Ручная арматура, в первом приближении, является статической системой, расчет которой можно проводить статическими методами. Электроприводная арматура, в большинстве случаев включающая асинхронный электродвигатель, - система электродинамическая. При закрытии арматуры с прямолинейным направлением движения запирающего элемента (клапан, задвижка) в системе возникают процессы, аналогичные режиму «короткого замыкания». Токи в момент закрытия системы могут превысить номинальное значение в 5-10 ра3, соответственно, и крутящие моменты при закрытии за короткий промежуток времени многократно увеличиваются. Чем больше «временная задержка» при срабатывании системы управления электродвигателем, которая на практике может достигать 100 мс, тем выше значение крутящих моментов [8, 16]. В результате приращения крутящего момента в запорной арматуре со стороны электропривода возникают существенные нагрузки, снижающие надежность систем при эксплуатации $[11,14]$.

Следовательно актуальной задачей является разработка методики силового расчета электроприводной арматуры. Цель работы - определение величины крутящего момента отключения электропривода, который с учетом электродинамических процессов обеспечит надежное запирание арматуры, т.е. позволит гарантировать соответствие фактического крутящего момента при полной остановке системы расчетному крутящему моменту, установленному статическими методами и подтвержденному многолетним опытом эксплуатации.

Основные положения методики. В основу методики были положены следующие положения:

1. Электроприводная арматура - техническая система, включающая в свою структуру три основных элемента: электропривод, запорную арматуру и систему управления электродвигателем. Изменение параметров любого их элементов приводит к изменению выходных характеристик системы в целом $[4,5]$.

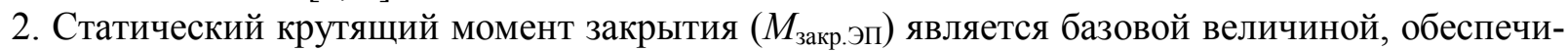
вающей надежное функционирование эксплуатирующих систему объектов. Следовательно, кру-

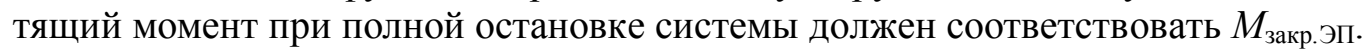

3. Методика должна учитывать минимальный набор наиболее важных характеристик элементов, влияющих на выходные характеристики системы $[10,12]$.

Суть методики. По результатам многочисленных теоретических и экспериментальных ис-

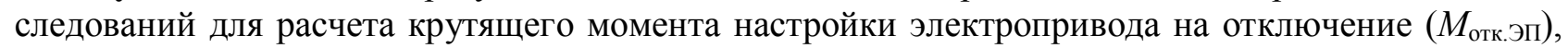
достаточного для надежного запирания арматуры, предложена формула [2]

$$
M_{\text {откл.эп }}=M_{\text {закр.эп }}-6 n_{\text {эп }} K_{i} \Delta \mathrm{T} \lambda,
$$

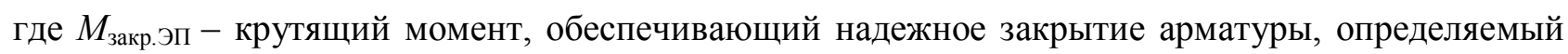

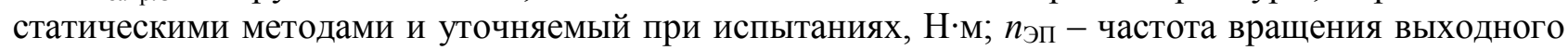
вала электропривода, об/мин; $\lambda$ - жесткость системы, Н·м/град; $K_{i}$ - эмпирический коэффициент, зависящий от времени запаздывания $\Delta t$ системы управления (СУ) и определяемый по формуле

$$
K_{i}=1,1^{i},
$$

где $i$ - порядковый номер временной задержки.

Параметры для назначения корректирующего эмпирического коэффициента задержки следующие:

$$
\begin{array}{ccccccccc}
i & 0 & 1 & 2 & 3 & 4 & 5 & 6 & 7 \\
\Delta t, \mathrm{c} & 0,01 & 0,02 & 0,03 & 0,04 & 0,05 & 0,06 & 0,07 & 0,08
\end{array}
$$

Формула (2) учитывает основные характеристики каждого из элементов, совмещаемых в технической системе (ТC), и на стадии проектирования позволяет рассчитать крутящий момент отключения электропривода при известных значениях всех основных параметров системы: жесткости системы $\lambda$, частоты вращения выходного вала электропривода $n_{\text {эп, }}$ временной задержки срабатывания системы управления $\Delta t$.

Жесткость системы $\lambda$ - демпфирующая составляющая [13]. Повышение жесткости увеличивает фактическое значение крутящего момента [6]. Следует отметить, что по настоящее время методики расчета жесткости электроприводной арматуры не существует. Для определения значения этого параметра можно использовать данные табл.1. 
Зависимость жесткости системы от номинального крутящего момента и диапазона настройки электропривода

\begin{tabular}{|c|c|c|}
\hline Диапазон настройки ЭП по крутящему моменту, Н·м & $M_{\text {ном }}, \mathrm{H} \cdot \mathrm{M}$ & Жесткость системы средняя (минимальная; максимальная), Н·м/град \\
\hline $\begin{array}{c}40-120 \\
100-250 \\
200-500\end{array}$ & $\begin{array}{c}80 \\
175 \\
350\end{array}$ & $\begin{array}{c}10(6,3 ; 16) \\
25(16 ; 40) \\
63(40 ; 100)\end{array}$ \\
\hline
\end{tabular}

В табл.1 представлены результаты анализа, которые позволили установить связь между жесткостью системы и диапазоном настройки электропривода (ЭП) по крутящему моменту для управления различными запорными клапанами. Усредненное значение жесткости (табл.1) можно определить и по номинальному крутящему моменту ЭП $\left(M_{\text {ном }}\right)$ в указанных пределах диапазона настройки.

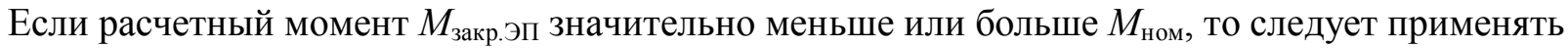
наименьшую или наибольшую жесткость из ряда предпочтительных значений, указанных в скобках (табл.1).

Значение частоты вращения выходного вала $\left(n_{\text {эп }}\right)$ определяется в соответствии с техническими условиями (ТУ) на электропривод. Влияние данного параметра на выходные характеристики ТС достаточно весомое. С увеличением частоты вращения фактическое значение крутящего момента, фиксируемое при полной остановке системы, увеличивается практически прямо пропорционально.

Временная задержка срабатывания системы управления $(\Delta t)$ определяется как сумма задержек всех компонентов СУ. Значение данного параметра ограничено стандартами и должно составлять не более $100 \mathrm{Mc}(0,1 \mathrm{c})$.

Значения крутящего момента настройки электропривода, рассчитанные в соответствии с формулой (2), на стадии испытаний опытных образцов необходимо подтверждать и при необходимости корректировать. Наиболее простым и надежным методом для уточнения реального крутящего момента отключения ЭП является «метод протечек». Его можно применять как на стадии

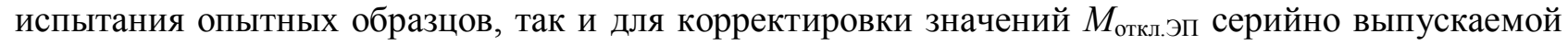
арматуры, уже находящейся в эксплуатации.

Алгоритм предлагаемого метода можно представить в следующем виде:

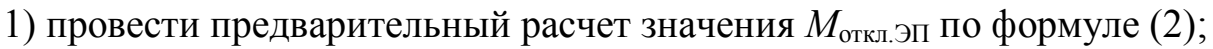

2 ) настроить систему в соответствии с полученным расчетным крутящий моментом $M_{\text {откл.эп; }}$

3) установить электроприводную арматуру на испытательный стенд, подключить электропитание и подать рабочую среду под давлением (рис.1);

4) произвести запуск системы и выполнить пять полных циклов. Под полным циклом понимается совершение запорным органом хода из положения «закрыто» в положение «открыто» и обратно;

5) по истечению пяти полных циклов остановить систему и определить протечку воздуха в затворе. Протечка определяется путем подсчета числа пузырьков воздуха, выходящего из насадки, подсоединенной к выходному патрубку арматуры и погруженной в емкость с водой, по формуле

$$
q_{\text {возд }}=\frac{N_{\text {пуз }} V_{\text {пуз }}}{\tau},
$$

где $q_{\text {возд }}-$ протечки в затворе, $\mathrm{cm}^{3} /$ мин; $N_{\text {пуз }}-$ измеренное число пузырьков воздуха; $V_{\text {пуз }}$ объем пузырька воздуха (указанный в табл. Г.7 в зависимости от внутреннего диаметра

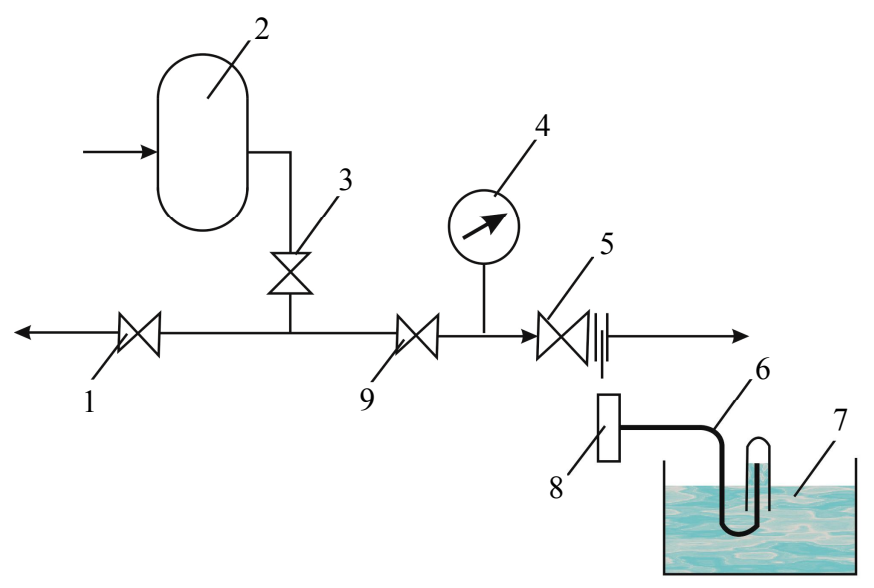

Рис.1. Принципиальная схема испытательного стенда 1, 3, 9 - запорно-регулирующий клапан; 2 - источник давления; 4 - прибор для измерения давления; 5 - испытуемая электроприводная арматура; 6 - мензурка; 7 - емкость с водой; 8 - заглушка с трубкой 
насадки - ГОСТ Р 53402-2009 «Арматура трубопроводная. Методы контроля и испытаний. М.: Стандартинформ, 2010. 54 с.), см$^{3} ; \tau-$ время измерения, мин;

6) если протечка отсутствует или находится в пределах допуска, то необходимо уменьшить

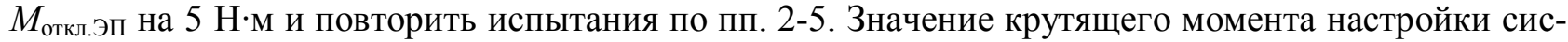
темы снижать до появления протечки или до достижения предельного значения ограничителем крутящего момента;

7) если после первичной настройки системы на крутящий момент отключения $M_{\text {откл.эп про- }}$ течка будет зафиксирована сразу, то необходимо увеличить $M_{\text {откл.эп }}$ на 5 Н·м и повторить испытания по пп. 2-5. Значение крутящего момента настройки системы можно увеличить не более чем в 1,5 раза либо до достижения максимального предельного значения ограничителем крутящего момента. При этом следует понимать, что в описанной ситуации велика вероятность брака арматуры, наличие которого необходимо исключить.

Описанный алгоритм позволяет уточнить значение крутящего момента настройки электропривода, при котором система обеспечит надежное запирание среды («момент на грани протечки»). Учитывая, что из-за технологических допусков изготовления для каждой системы установленное значение будет индивидуальным, но отличия эти не критические, в пределах $\pm 5 \%$, в ТУ на изделие значение крутящего момент настройки ЭП на отключение необходимо указывать с коэффициентом запаса:

$$
M_{\text {откл.ЭП }}^{\text {ТУ }}=1,2 M_{\text {откл.ЭП }}^{\text {экспер }}
$$

Пример реализации методики. Для подтверждения работоспособности методики был проведен расчет и уточнение параметров настройки реальной системы электроприводной арматуры (рис.2).

Система включала следующие элементы: электропривод (частота вращения выходного вала $n_{\text {эп }}=32$ об/мин, пределы регулирования муфты ограничения крутящего момента 100-250 Н·м); запорный клапан (условный проход 50 мм; крутящий момент, обеспечивающий надежное закрытие арматуры, определенный статическими методами и указанный в действующих ТУ $\left.M_{\text {закр.эп. }}=180 \mathrm{H} \cdot \mathrm{M}\right)$; блок управления (временная задержка $\Delta t=20 \mathrm{Mc}$ ).

Эмпирический коэффициент, зависящий от времени запаздывания СУ, был рассчитан по формуле (3), в соответствии с приведенными данными $K_{i}=1,1^{1}$.

Жесткость запорного клапана $\lambda=25 \mathrm{H} \cdot \mathrm{m} /$ град в соответствии с данными табл.1.

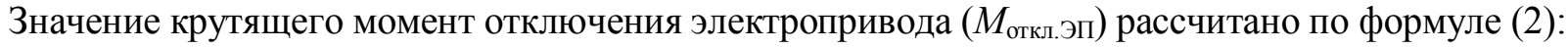

$$
M_{\text {откл.ЭП }}=180-6 \cdot 32 \cdot 1,1^{1} \cdot 0,02 \cdot 25=74,4 \mathrm{H} \cdot \mathrm{M} \text {. }
$$

По результатам расчета установлено, что крутящий момент, указанный в действующих ТУ $(180 \mathrm{H} \cdot \mathrm{M})$, существенно выше расчетного значения, полученного при использовании разрабо-

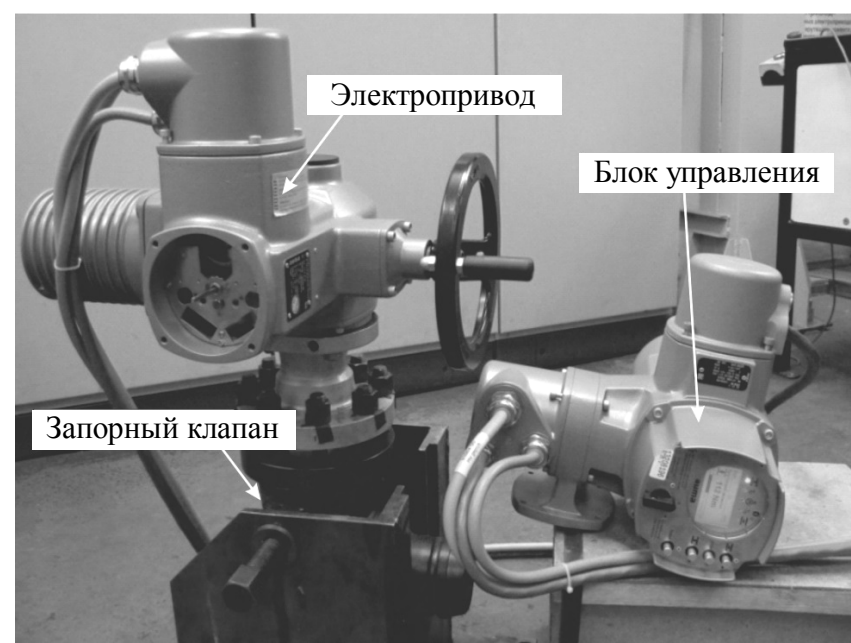

Рис.2.Система электроприводной запорной арматуры танной методики.

Пределы регулирования ЭП (100-250 Н·м) не позволили произвести настройку системы на новое расчетное значение $\left(M_{\text {откл.эп }}=\right.$ $=74,4 \mathrm{H} \cdot \mathrm{M})$ для уточнения параметров путем проведения испытаний на протечки. Для чистоты эксперимента ЭП реальной системы был настроен на крутящий момент отключения, соответствующий предельному минимальному значению (100 Н·м). Дополнительно проведены испытания для новой системы с идентичными характеристиками, но с меньшими пределами регулирования муфты ограничения крутящего момента (40-120 H·м), что позволило в процессе проведения испытаний максимально приблизиться к значению 

данного типа клапана составляют $30 \mathrm{~cm}^{3} /$ мин.

Анализируя полученные результаты (табл.2), можно сделать вывод, что зафиксированные значения протечек в затворе клапана не превышают установленного значения. Это доказывает работоспособность предложенной методики и возможность снижения моментов настройки ЭП в системе электроприводной арматуры с прямолинейным движением запирающего элемента без потери герметичности затвора запорного клапана.

\section{Выводы}

1. Разработана новая методика определения величины крутящего момента электропривода для настройки системы электроприводной арматуры с прямолинейным переклапана, см $^{3} /$ мин

\begin{tabular}{c|c|c}
\hline \multirow{2}{*}{$\begin{array}{c}\text { Количество } \\
\text { циклов }\end{array}$} & \multicolumn{2}{|c}{ Пределы регулирования ЭП, Н·м } \\
\cline { 2 - 3 } & $100-250$ & $40-120$ \\
\hline 250 & 0 & 0 \\
750 & 0 & 0 \\
1250 & 0 & 0 \\
1750 & 1,2 & 0 \\
2000 & 4,8 & 0 \\
2250 & 6,0 & 0 \\
2500 & 8,7 & 0 \\
2750 & 9,1 & $0,7^{*}$ \\
3000 & 11,0 & $3,2^{* *}$ \\
\hline
\end{tabular}

${ }^{*}$ С 2501-го по 2700-й циклы настройка

ЭП соответствовала $M_{\text {откл.эп }}^{\text {экер }}=90 \mathrm{H} \cdot \mathrm{M}$.

${ }^{* *}$ С 2701-го по 3000-й циклы настройка

ЭП соответствовала $M_{\text {откл. эп }}^{\text {экпер }}=80 \mathrm{H} \cdot \mathbf{м}$. мещением запорного органа (клапан, задвижка).

2. Методика позволяет при минимальном объеме входной информации о характеристиках элементов системы (электропривода, запорной арматуры, системы управления) произвести расчет достаточного значения крутящего момента настройки электропривода и гарантировать соответствие фактического крутящего момента при полной остановке системы расчетному крутящему моменту, установленному статическими методами.

3. Для уточнения параметров настройки проектируемых или находящихся в эксплуатации систем предложен экспериментальный метод - «метод протечек». В основу метода положена методика испытаний на герметичность запорной арматуры с пошаговым снижением крутящего момента электропривода до предельного значения - минимального крутящего момента, ограниченного пределами регулирования электропривода.

4. Использование методики на стадии проектирования позволяет при эксплуатации систем снизить нежелательные нагрузки, возникающие в запорной арматуре со стороны электропривода, обеспечивая надежную работу трубопроводных систем, транспортирующих минеральное сырье.

\section{ЛИТЕРАТУРА}

1. Абрамович Б.Н. Проблемы обеспечения энергетической безопасности предприятий минерально-сырьевого комплекса / Б.Н. Абрамович, Ю.А. Сычев // Записки Горного института. 2016. Т. 217. С. 132-139.

2. Васин С.A. Практический опыт обеспечения качества технических систем при взаимодействии производителей в общем потоке создания ценности конечного продукта / С.А.Васин, Е.В.Плахотникова // Управление качеством в нефтегазовом комплексе. 2017. № 1. С. 37-39.

3. Гуревич Д.Ф. Расчет и конструирование трубопроводной арматуры. Л.: Машиностроение, 1969. 887 с.

4. Максаров В.В. Моделирование и управление динамическими свойствами технологических систем / В.В.Максаров, П.В.Леонидов // Записки Горного института. 2014. Т. 209. С. 71-77.

5. Максаров В.B. Теория и практика моделирования и управления в области прогнозирования динамических свойств технологических систем / В.В.Максаров, Ю.Ольт // Металлообработка. 2012. № 2 (68). С. 5-12.

6. Плахотникова E.B. Результаты исследования систем «электропривод - запорная арматура» с позиции технической эффективности и энергопотребления // Известия ТулГУ. Технические науки. Тула: Изд-во ТулГУ, 2016. Вып. 3. С. $230-237$.

7. СТ ЦКБА 002-2003 Арматура трубопроводная. Задвижки. Методика силового расчета. СПб: НПФ ЦКБА, 2003. 69 с.

8. Шпаков О.Н. О расчетах нагрузок в электроприводной арматуре // Арматуростроение. 2005. № 5. С. 48-51.

9. Antsev V.Y. Improvement in production process for pipelines manufacturing based on quality management method/ V.Y.Antsev, N.A.Vitchuk, V.V.Miroshnikov // Procedia Engineering. Ser. «International Conference on Industrial Engineering, ICIE 2017». St. Petersburg: Saint-Peterburg Polytechnic University, 2017. P. 950-957.

10. Gorlenko $O$. Development of management methodology for engineering production quality / O.Gorlenko, V.Miroshnikov, N.Borbatc // IOP Conference Series: Materials Science and Engineering. International Conference on Mechanical Engineering, Automation and Control Systems 2015, MEACS 2015. 2016. P. 66-70. DOI: 10.1088/1757-899X/124/1/012012

11. Dynamic synthesis of technological equipment for the manufacture of precision articles/ A.G. Ivakhnenko, V.V.Kuts, A.Yu.Altukhov, E.O.Ivakhnenko // Chemical and Petroleum Engineering. 2015. Vol. 51. № 7. P. 445-451. DOI: 10.1007/s10556015-0066-4 
Методика расчета величины крутящего момента...

12. Maksarov $V$. Determining the load on support rollers the pipe conveyor belt / V.Maksarov, E.Zlotnikov, J.Olt // Annals of DAAAM and Proceedings of the International DAAAM Symposium. 2017. P.0209-0215. DOI: 10.2507/28th.daaam.proceedings.028

13. Maksarov V.V. Dynamic Stabilization of Technological Systems for Processing Edge Cutting Through Local Metstability / V.V.Maksarov, J.Olt, M.Madissoo // USB Proceedings. IEEE International Symposium on Assembly and Manufacturing, 25th-27th May 2012, Tampere Hall. Tampere, Finland. P. 6-12.

14. Plakhotnikova Elena V. Quality and Competitiveness Improvement of NPP Safety Systems // IEEE Conference on quality management, transport and information security, information technologies (IT\&MQ\&IS). Nalchik, Russia, 2016. P. 41-42. DOI: 10.1109/ITMQIS.2016.7751946

15. Rudenko A.A. Increase of stability of functioning of a production system of machine-building enterprise/ A.A.Rudenko, D.V.Antipov, M.O.Iskoskov // IOP Conference Series: Materials Science and Engineering 6. Ser. «6th International Scientific Practical Conference on Innovative Technologies and Economics in Engineering». 2015. P. 012-071. DOI:10.1088/1757$899 X / 91 / 1 / 012071$

16. Zhou K. A review of electrical load classification in smart grid environment/ K.Zhou, S.Yang, C.Shen // Renewable \& Sustainable Energy Reviews. 2013. Vol. 24. P. 103-110.

Авторы: С.А.Васин, д-р техн. наук, профессор, vasin_sa53@таіl.rи (Тульский государственный университет, Тула, Россия), Е.В.Плахотникова, д-р техн. наук, доиент, plahotnikova@mail.ru (Тульский государственный университет, Тула, Россия).

Статья поступила в редакичию 03.03.2018.

Статья принята к публикации 15.04.2018. 